\title{
The shrinking health advantage: unintentional injuries among children and youth from immigrant families
}

\author{
Natasha Ruth Saunders ${ }^{1,2,3,4^{*}}$, Alison Macpherson ${ }^{3,5}$, Jun Guan ${ }^{3}$, Lisa Sheng ${ }^{3}$ and Astrid Guttmann 1,2,3,4,6
}

\begin{abstract}
Background: Immigrants typically arrive in good health. This health benefit can decline as immigrants adopt behaviours similar to native-born populations. Risk of injury is low in immigrants but it is not known whether this changes with increasing time since migration. We sought to examine the association between duration of residence in Canada and risk of unintentional injury.

Methods: Population-based cross-sectional study of children and youth 0 to 24 years in Ontario, Canada (2011-2012), using linked health and administrative databases. The main exposure was duration of Canadian residence (recent: 0-5 years, intermediate: 6-10 years, long-term: $>10$ years). The main outcome measure was unintentional injuries. Cause-specific injury risk by duration of residence was also evaluated. Poisson regression models estimated rate ratios (RR) for injuries.
\end{abstract}

Results: 999951 immigrants were included with 24.2\% recent and 26.4\% intermediate immigrants. The annual crude injury rates per 100000 immigrants were 6831 emergency department visits, 151 hospitalizations, and 4 deaths. In adjusted models, recent immigrants had the lowest risk of injury and risk increased over time (RR 0.79; 95\% Cl 0.77, 0.81 recent immigrants, RR 0.90; 95\% Cl 0.88, 0.92 intermediate immigrants, versus long-term immigrants). Factors associated with injury included young age (0-4 years, RR 1.30; $95 \% \mathrm{Cl} 1.26,1.34)$, male sex (RR 1.52; 95\% Cl 1.49, 1.55), and high income (RR 0.93; 95\% Cl 0.89, 0.96 quintile 1 versus 5). Longer duration of residence was associated with a higher risk of unintentional injuries for most causes except hot object/scald burns, machinery-related injuries, non-motor vehicle bicycle and pedestrian injuries. The risk of these latter injuries did not change significantly with increasing duration of residence in Canada. Risk of drowning was highest in recent immigrants.

Conclusions: Risk of all-cause and most cause-specific unintentional injuries in immigrants rises with increasing time since migration. This indicates the need to develop strategies for maintaining the immigrant health advantage over time while balancing the desire to support integration, active living, and healthy child development.

Keywords: Immigration, Pediatric, Migration

\section{Background}

With the proliferation of global migration, increasing attention is being paid to health outcomes of immigrants in developed countries. Immigrants tend to arrive with better health than their native born counterparts. This healthy immigrant effect has been demonstrated across multiple health systems, in several

\footnotetext{
* Correspondence: Natasha.saunders@sickkids.ca

'The Hospital for Sick Children, 555 University Avenue, Toronto, Ontario M5G $1 \times 8$, Canada

${ }^{2}$ Department of Pediatrics, University of Toronto, Toronto, Canada Full list of author information is available at the end of the article
}

countries, and for a number of conditions [1-7]. With increasing duration of residence in a host country, this health benefit can shrink as immigrants adopt behaviours and exposures more similar to the native population. This latter observation, demonstrated in adult populations, has been termed the "convergence hypothesis" $[4,8,9]$.

The notion of the healthy immigrant effect has been less well studied in children and young adults but has been shown for immunizations [10], mental health $[1,11]$, and substance use [1]. The convergence 
hypothesis, however, has not been evaluated at a population-based level for pediatric health outcomes. Moreover, in adults, there is considerable variation in the effects of immigration on health and its subsequent convergence towards the native population depending on the health outcome and region of origin $[8,9]$.

Injury remains one of the leading causes of death, hospitalization, and emergency department (ED) visits for children and youth in North America and Europe $[12,13]$. Most injuries are preventable, and injury reduction strategies, when targeted and implemented appropriately, are successful [14-16]. Immigrants have a lower risk of unintentional injury than Canadian born children [17-19]. Though there is some cause-specific variability, this has been demonstrated across all causes of injury [19]. The evidence for the extent to which the lower risk of injury persists with increasing duration of residence in a new country for children and young adults from immigrant families is not known. As immigrant populations acculturate, their risk-taking behaviours or exposures may change. Investigating patterns of injury across immigrant populations with increasing time since migration can help provide a more comprehensive picture of contributing factors to injury risk in this large and growing population. With better understanding of unintentional injury risk in immigrants, strategies can be developed for injury prevention, education, behaviour modification, and policy development so that immigrants can maintain their health advantage.

We sought to examine patterns of unintentional injury in children and youth from immigrant families in a large, diverse Canadian province with a single payer health care system where $20 \%$ of the population are immigrants [20]. Our specific objectives were to describe the epidemiology of unintentional injury-related emergency department visits, hospitalizations, and deaths overall and according to cause of injury in recent, intermediate-term, and long-term children and youth from immigrant families and by region of origin; and to test the association of unintentional injury and duration of residence and region of origin in children from immigrant families in Ontario, Canada.

\section{Methods}

\section{Study Design}

This population-based cross-sectional study was carried out at the Institute for Clinical Evaluative Sciences (ICES) using multiple, linked health and administrative databases (Fig. 1) through a research agreement with the Ontario Ministry of Health and Long-Term Care. Research ethics board approval was obtained from The Hospital for Sick Children and Sunnybrook Health Sciences Centre in Toronto, Ontario.

\section{Dataset Sources}

The Ontario Health Insurance Plan (OHIP) is the singlepayer, universal funding plan for medically necessary physician and hospital services in Ontario. Permanent residents admitted to Canada as immigrants or refugees are typically eligible for OHIP within 3 months of living in Ontario. OHIP eligible persons are entered into Ontario's health care registry, the Registered Persons Database (RPDB), which contains socio-demographic information about residents including their age, sex, and postal code. Their OHIP number is encoded and linked to a number of other health administrative and demographic databases. The Canadian Institute for Health Information (CIHI) Discharge Abstract Database (DAD) and National Ambulatory Care Reporting System (NACRS) provide standard data collection and reporting tools to capture hospitalization and emergency department visit information, respectively, and include the main diagnosis. Linkage rates to the RPDB are greater than 97\% [21]. These were used to obtain injury-related information where a hospital or ED visit occurred. The Ontario Registrar General - Death (Vital Stats) was used to identify in and out of hospital injury-related deaths in Ontario. Neighbourhood income quintile was obtained using Statistics Canada's Postal Code Conversion File to link a patient's postal code at the dissemination area level (400 to 700 persons) based on the 2006 Canadian Census [22].

The Permanent Resident Data System, a federal database maintained by Immigration, Refugees and Citizenship Canada (IRCC), holds socio-demographic and immigration information on all permanent residents landing in Ontario from January $1^{\text {st }}, 1985$ to the present. Permanent residents are immigrants who have been granted to the right to stay and work in Canada without limitations on their stay. It does not include data on temporary or undocumented immigrants. Information is collected from official immigration documents upon landing. The MOMBABY database is an ICES derived database that pairs all mothers with their newborns, delivered in hospital in Ontario through linkage of the CIHI-DAD inpatient admission records of delivering mothers and their newborns [21]. This was used to identify newborns born in Canada to immigrant mothers.

\section{Study Population}

The study population included children and youth from birth to 24 years of age who were immigrants, or were born in Canada to immigrant mothers. To be included, individuals must have had an IRCC permanent resident record or be the child of a mother with an IRCC record and have a linked mother-baby dyad in the ICES MOMBABY database. Maternal immigrant status was included to reflect the influence of family immigrant status, rather than that of only the child. Parental health and risk-taking behaviours are particularly important for a child's risk of 


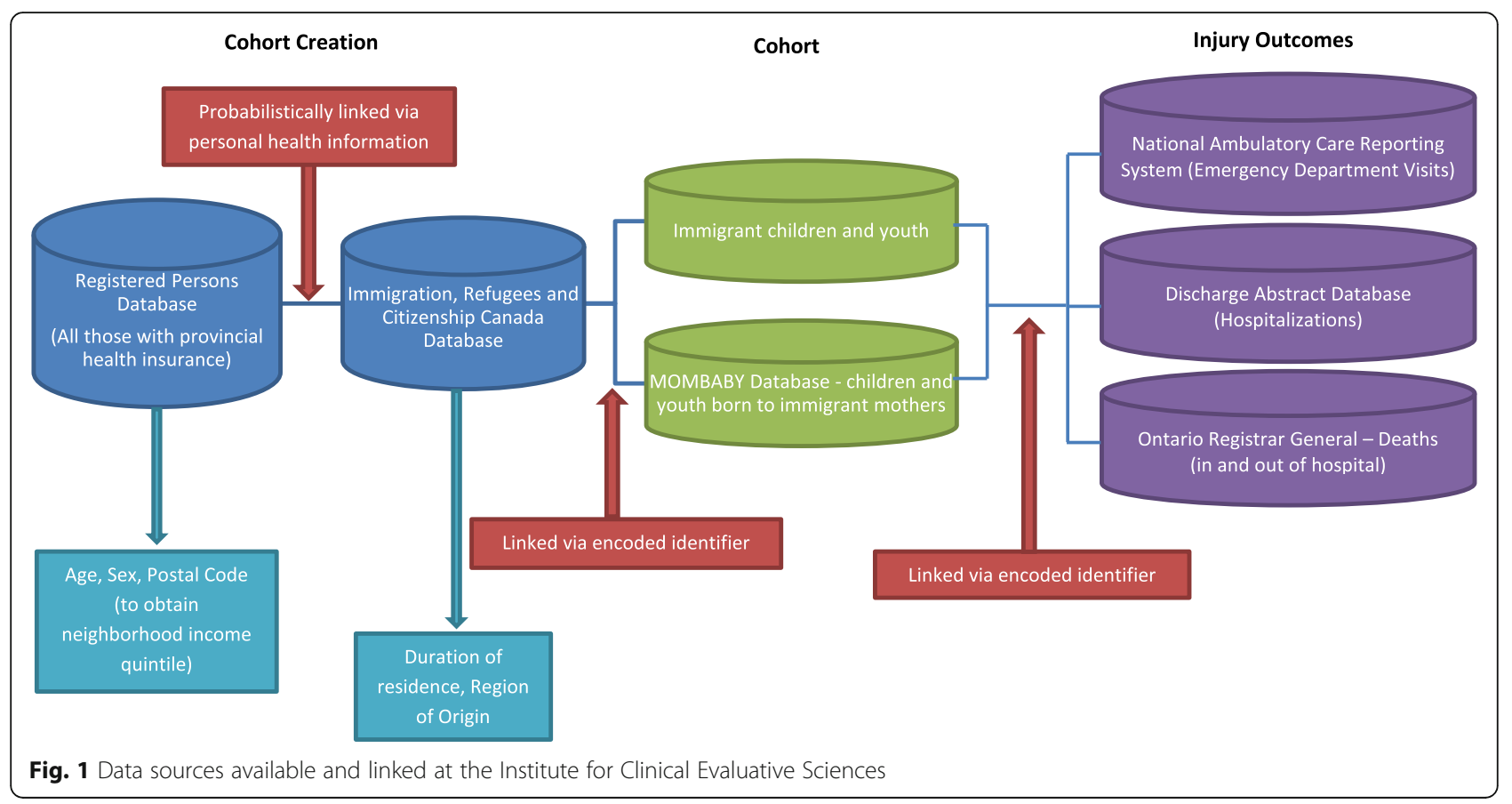

injury (e.g. safe sleeping and cooking environments, car seat safety, etc.) Moreover, maternal immigrant status is associated with risk of injury in children [19, 23]. Individuals must have been residing in Ontario with a valid Ontario Health Insurance Plan (OHIP) number between January $1^{\text {st }} 2011$ and December $31^{\text {st }}, 2012$.

\section{Outcome Measures}

The main outcome measure was an unintentional injury-related visit to an ED or a hospitalization, or an unintentional injury related death (in and out of hospital) during the study window (2011 to 2012). The International Classification of Disease 10-CM External Cause of Injury Codes were used to identify and group injuries by cause [24]. Multiple events by the same patient were included although only one event per patient per day was included. Where individuals had an ED visit with a subsequent hospitalization, only the hospitalization was counted. Duplicate, overlapping, or transferred ED visits were not double counted so that only the first record for any given injury event was considered.

\section{Exposure Variables}

The main exposure was duration of residence in Canada. Immigrants were grouped as recent ( 0 to 5 years in Canada), intermediate-term (6 to 10 years in Canada), and long-term (greater than 10 years in Canada). Duration of residence was determined from the difference of the number of years from the date of landing to December $31^{\text {st }}$, 2011 (study mid-point). If the patient was born in Canada to an immigrant mother, the duration of residence was calculated based on the maternal immigration information. The secondary exposure was region of origin, based on the country of birth, using modified IRCC region groupings [20].

\section{Covariates}

A number of covariates that have been shown to be associated with risk of unintentional injury were considered. Older age (adolescence) is a strong predictor of injury risk, as is male sex $[17,25]$. Both age and sex were therefore included as covariates. In a number of populations, low income has been associated with an increased risk of both unintentional and intentional injury $[23,26]$. We therefore included postal code based neighbourhood income quintiles within dissemination areas (areas of 400 to 700 individuals) from health records as a covariate.

\section{Statistical Analysis}

Descriptive statistics were performed for the main independent variables, outcome variables, and covariates. The crude injury rates were calculated, as were the total number of events. To compare outcomes of immigrants by duration of residence, multiple variable Poisson regression models adjusting for overdispersion were used to compute rate ratios with $95 \%$ confidence intervals. A sensitivity analysis excluding children and youth of immigrant mothers was also performed. For each model, variables were selected $a$ priori and included in the regression analysis. The cause-specific rate ratios of injury by duration of residence was also calculated using multiple variable Poisson regression models adjusting for overdispersion. All 
statistical modelling was carried out using SAS Enterprise Guide, version 6.1 (SAS Institute Inc., Cary, NC).

\section{Results}

There were 999951 children and youth included in the study. Compared with long-term immigrants, recent immigrants had a greater proportion of young and lower neighbourhood income quintile individuals (Table 1). Most (49.5\%) immigrants were from South and East Asia. The annual crude rates of unintentional injuries per 100000 were 6830 for ED visits, 151 for hospitalizations, and 4 deaths.

Table 2 shows the rates of unintentional-injury events by duration of residence and region of origin. Compared with recent immigrants, immigrants living in Canada for more than 10 years had higher rates of ED visits and hospitalizations for injuries across all age groups, income quintiles, and regions of origin with the exceptions of hospitalizations among 10- to 14-year-olds and Central
Americans and emergency department visits among those from South America where rates were relatively unchanged. Immigrants from East and South Asia had the lowest rates of unintentional injury, and those from the United States/United Kingdom/Europe, Central Asia, and South America had the highest rates.

In the multiple variable Poisson regression model (Table 3), after adjusting for age, sex, income quintile, and region of origin, recent immigrants had significantly lower rates of unintentional injury and this risk increased over time (rate ratio $[R R]=0.79,95 \%$ confidence interval [CI] $0.77,0.81$ for recent immigrants, $\mathrm{RR}=0.90 ; 95 \%$ CI $0.88,0.92$ for intermediate immigrants compared to long-term immigrants). Sensitivity analysis excluding children and youth born to immigrant mothers (Additional file 1: Tables S1 and S2), excluding infants less than one year (Additional file 2: Tables S3 and S4), and excluding those with missing region of origin (Additional file 3: Table S5) showed

Table 1 Children and youth from immigrant families in Ontario by duration of residence, 2011 to 2012

\begin{tabular}{|c|c|c|c|c|c|c|c|c|}
\hline & \multicolumn{2}{|l|}{$\underline{\text { Overall }}$} & \multicolumn{2}{|l|}{ Recent } & \multicolumn{2}{|c|}{$\underline{\text { Intermediate }}$} & \multicolumn{2}{|c|}{ Long-term } \\
\hline & $\mathrm{N}$ & $\%$ & $\mathrm{~N}$ & $\%$ & $\mathrm{~N}$ & $\%$ & $\mathrm{~N}$ & $\%$ \\
\hline Overall & 999951 & 100.0 & 242117 & 24.2 & 264453 & 26.4 & 493381 & 49.3 \\
\hline \multicolumn{9}{|l|}{ Age (years) } \\
\hline $0-4$ & 227965 & 22.8 & 77930 & 32.2 & 72572 & 27.4 & 77463 & 15.7 \\
\hline $5-9$ & 197813 & 19.8 & 39394 & 16.3 & 64870 & 24.5 & 93549 & 19.0 \\
\hline $10-14$ & 199438 & 19.9 & 40005 & 16.5 & 42240 & 16.0 & 117193 & 23.8 \\
\hline $15-19$ & 198308 & 19.8 & 39465 & 16.3 & 43319 & 16.4 & 115524 & 23.4 \\
\hline $20-24$ & 176427 & 17.6 & 45323 & 18.7 & 41452 & 15.7 & 89652 & 18.2 \\
\hline \multicolumn{9}{|l|}{ Sex } \\
\hline Female & 486604 & 48.7 & 119032 & 49.2 & 127978 & 48.4 & 239594 & 48.6 \\
\hline Male & 513347 & 51.3 & 123085 & 50.8 & 136475 & 51.6 & 253787 & 51.4 \\
\hline \multicolumn{9}{|l|}{ Income quintile } \\
\hline Q1-lowest income & 290151 & 29.0 & 90836 & 37.5 & 77208 & 29.2 & 122107 & 24.7 \\
\hline Q2 & 216221 & 21.6 & 52924 & 21.9 & 57026 & 21.6 & 106271 & 21.5 \\
\hline Q3 & 201353 & 20.1 & 42239 & 17.4 & 53734 & 20.3 & 105380 & 21.4 \\
\hline Q4 & 177852 & 17.8 & 34777 & 14.4 & 48029 & 18.2 & 95046 & 19.3 \\
\hline Q5-highest income & 114374 & 11.4 & 21341 & 8.8 & 28456 & 10.8 & 64577 & 13.1 \\
\hline \multicolumn{9}{|l|}{ Source region } \\
\hline E.Asia/Pacific & 226268 & 22.6 & 56714 & 23.4 & 61623 & 23.3 & 107931 & 21.9 \\
\hline S.Asia & 268939 & 26.9 & 68532 & 28.3 & 88598 & 33.5 & 111809 & 22.7 \\
\hline E.Europe/Central Asia & 75865 & 7.6 & 14075 & 5.8 & 23425 & 8.9 & 38365 & 7.8 \\
\hline Africa & 90135 & 9.0 & 23712 & 9.8 & 20981 & 7.9 & 45442 & 9.2 \\
\hline Middle East & 95966 & 9.6 & 31668 & 13.1 & 26491 & 10.0 & 37807 & 7.7 \\
\hline S.America & 48259 & 4.8 & 10555 & 4.4 & 11573 & 4.4 & 26131 & 5.3 \\
\hline Central America & 84007 & 8.4 & 15796 & 6.5 & 12035 & 4.6 & 56176 & 11.4 \\
\hline US/UKWestern Europe & 110178 & 11.0 & 21034 & 8.7 & 19693 & 7.4 & 69451 & 14.1 \\
\hline Missing & 334 & 0.0 & 31 & 0.0 & 34 & 0.0 & 269 & 0.1 \\
\hline
\end{tabular}


Table 2 Unintentional injury related emergency department (ED) visits, hospitalizations, and deaths by duration of residence, annualized 2011 to 2012

\begin{tabular}{|c|c|c|c|c|c|c|c|c|c|}
\hline & \multicolumn{3}{|l|}{ ED visits } & \multicolumn{3}{|c|}{ Hospitalizations } & \multicolumn{3}{|l|}{ Deaths $^{a}$} \\
\hline & Recent & Intermediate & Long-term & Recent & Intermediate & Long-term & Recent & Intermediate & Long-term \\
\hline \multirow[t]{2}{*}{ Total events } & 12832 & 16610 & 35494 & 304 & 369 & 764 & 11 & 10 & 21 \\
\hline & \multicolumn{3}{|c|}{ Rate per 100000 immigrants } & \multicolumn{3}{|c|}{ Rate per 100000 immigrants } & \multicolumn{3}{|c|}{ Rate per 100000 immigrants } \\
\hline Overall Injury Rate & 5866.2 & 6521.9 & 7437.0 & 138.8 & 144.9 & 160.1 & 4.8 & 3.9 & 4.3 \\
\hline \multicolumn{10}{|l|}{ Age (years) } \\
\hline $0-4$ & 7133.4 & 7985.5 & 8824.0 & 164.9 & 163.4 & 214.7 & - & - & - \\
\hline $5-9$ & 5043.1 & 5886.6 & 6552.4 & 137.9 & 164.8 & 157.0 & - & - & - \\
\hline $10-14$ & 5579.1 & 6134.3 & 7523.5 & 134.0 & 96.2 & 131.3 & - & - & - \\
\hline $15-19$ & 5594.0 & 5856.1 & 7295.8 & 131.5 & 142.4 & 155.4 & - & - & - \\
\hline $20-24$ & 4922.2 & 6191.5 & 7311.2 & 104.1 & 134.9 & 163.9 & - & - & - \\
\hline \multicolumn{10}{|l|}{ Sex } \\
\hline Female & 4678.6 & 5187.1 & 5877.2 & 93.8 & 103.8 & 115.4 & - & - & 3.9 \\
\hline Male & 7006.1 & 7774.1 & 8910.3 & 181.9 & 183.4 & 202.3 & - & - & 4.7 \\
\hline \multicolumn{10}{|l|}{ Income quintile } \\
\hline Q1-lowest income & 5802.5 & 6280.4 & 7315.0 & 153.9 & 152.5 & 184.1 & - & - & 5.1 \\
\hline Q2 & 5599.9 & 6126.3 & 7068.5 & 129.6 & 135.8 & 152.8 & - & - & - \\
\hline Q3 & 5591.8 & 6356.9 & 7328.0 & 132.7 & 147.9 & 149.7 & - & - & - \\
\hline Q4 & 6323.5 & 6951.5 & 7697.8 & 133.7 & 138.6 & 151.8 & - & - & - \\
\hline Q5-highest income & 6554.3 & 7497.6 & 8053.0 & 118.6 & 147.6 & 156.4 & 0.0 & - & - \\
\hline \multicolumn{10}{|l|}{ Source region } \\
\hline E.Asia/Pacific & 4309.0 & 5289.1 & 5087.7 & 107.9 & 110.2 & 122.3 & - & - & - \\
\hline S.Asia & 5245.8 & 5530.0 & 6544.3 & 152.3 & 154.1 & 164.2 & - & - & - \\
\hline E.Europe/Central Asia & 7647.7 & 8423.2 & 9117.2 & 159.6 & 157.5 & 186.5 & - & - & - \\
\hline Africa & 6307.7 & 7524.4 & 8156.2 & 140.9 & 148.8 & 169.5 & - & - & - \\
\hline Middle East & 6316.2 & 7139.4 & 7708.5 & 146.0 & 154.1 & 131.1 & - & - & - \\
\hline S.America & 8466.5 & 8423.1 & 8408.3 & 134.9 & 171.3 & 197.7 & - & 0.0 & - \\
\hline Central America & 6912.7 & 8101.4 & 8404.1 & 189.1 & 174.5 & 171.5 & - & - & - \\
\hline US/UKW. Europe & 7513.8 & 8592.6 & 9852.4 & 115.4 & 146.2 & 184.6 & - & - & - \\
\hline Missing & 10344.8 & 3225.8 & 9807.7 & 0.0 & 0.0 & 0.0 & 0.0 & 0.0 & 0.0 \\
\hline
\end{tabular}

${ }^{a}$ Death rates for subgroups not reported due to small cell sizes. Institutional policy requires suppression of cell sizes $<6$ or where back-calculation could allow for identification of cell sizes $<6$

the direction of the effects of duration of residence did not change. Predictors of unintentional injury included young age $(0$ to 4 years, $\mathrm{RR}=1.30 ; 95 \% \mathrm{CI}$ $1.26,1.34)$ and male sex $(\mathrm{RR}=1.52 ; 95 \%$ CI 1.49 , 1.55). Higher income quintile was associated with increased risk of unintentional injury. The risk of injury was lowest in immigrants from Asia $(\mathrm{RR}=0.55 ; 95 \% \mathrm{CI}$ 0.53, 0.57 for East Asia/Pacific, RR $=0.67$; 95\% CI 0.64, 0.69 for South Asia).

Figure 2 shows the cause-specific risk of unintentional injury by duration of residence in Canada. Longer duration of residence was associated with a higher risk of unintentional injuries for most causes except hot object/ scald burns, machinery-related injuries, non-motor vehicle bicycle and pedestrian injuries. The risk of these latter injuries did not change significantly with increasing duration of residence in Canada. Moreover, risk of injury was highest in recent immigrants for drowning. In evaluating cause-specific injury by severity (i.e. those requiring hospitalization or causing death versus ED visit), similar patterns by duration of residence were observed in causespecific rates of injury (Table 4).

\section{Discussion}

In this large population-based cross-sectional study, we report longer duration of residence in Canada is 
Table 3 Rate ratios of unintentional injuries in children and youth aged 0-24 years by duration of residence, 2011-2012

\begin{tabular}{|c|c|c|}
\hline Duration of residence & $\begin{array}{l}\text { Unadjusted } \\
\text { rate ratios } \\
(95 \% \mathrm{Cl})\end{array}$ & $\begin{array}{l}\text { Adjusted }^{a} \\
\text { rate ratio } \\
(95 \% \mathrm{Cl})\end{array}$ \\
\hline Recent & $0.79(0.75,0.83)$ & $0.79(0.77,0.81)$ \\
\hline Intermediate & $0.88(0.84,0.92)$ & $0.90(0.88,0.92)$ \\
\hline Longer-term (reference) & 1 & 1 \\
\hline \multicolumn{3}{|l|}{ Age } \\
\hline 00-04 & $1.24(1.16,1.32)$ & $1.30(1.26,1.34)$ \\
\hline 05-09 & $0.94(0.88,1.00)$ & $0.94(0.91,0.98)$ \\
\hline $10-14$ & $1.06(0.99,1.13)$ & $1.05(1.01,1.08)$ \\
\hline $15-19$ & $1.03(0.96,1.10)$ & $1.01(0.98,1.05)$ \\
\hline 20-24 (reference) & 1 & 1 \\
\hline \multicolumn{3}{|l|}{ Sex } \\
\hline Male & $1.51(1.46,1.57)$ & $1.52(1.49,1.55)$ \\
\hline Female (reference) & 1 & 1 \\
\hline \multicolumn{3}{|l|}{ Income } \\
\hline Q1 & $0.87(0.81,0.93)$ & $0.93(0.89,0.96)$ \\
\hline Q2 & $0.85(0.79,0.91)$ & $0.91(0.88,0.94)$ \\
\hline Q3 & $0.88(0.82,0.95)$ & $0.92(0.89,0.96)$ \\
\hline Q4 & $0.95(0.88,1.02)$ & $0.97(0.94,1.01)$ \\
\hline $\begin{array}{l}\text { Q5-highest income } \\
\text { (reference) }\end{array}$ & 1 & 1 \\
\hline \multicolumn{3}{|l|}{ Source Regions } \\
\hline East Asia and Pacific & $0.54(0.51,0.58)$ & $0.55(0.53,0.57)$ \\
\hline South Asia & $0.65(0.61,0.68)$ & $0.67(0.64,0.69)$ \\
\hline Eastern Europe/Central Asia & $0.94(0.88,1.01)$ & $0.95(0.91,0.99)$ \\
\hline Africa & $0.82(0.77,0.88)$ & $0.85(0.81,0.88)$ \\
\hline Middle East & $0.77(0.72,0.83)$ & $0.81(0.78,0.84)$ \\
\hline South America & $0.92(0.85,1.00)$ & $0.94(0.89,0.98)$ \\
\hline Central America & $0.88(0.83,0.95)$ & $0.89(0.85,0.93)$ \\
\hline Missing & $0.98(0.44,2.20)$ & $0.97(0.60,1.56)$ \\
\hline US/UKWestern Europe (reference) & 1 & 1 \\
\hline
\end{tabular}

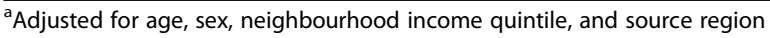

associated with an increased risk of unintentional injuries in children and young adults from immigrant families. This was observed across most causes of injury, except for drowning and scald burns where the highest rates of injury were among newcomers $(\leq 5$ years in Canada). Risk of unintentional injury was lowest in immigrants from South and East Asia and highest in those from Europe and the Americas.

The rates of unintentional injury in our cohort of immigrants are much lower than published rates for pediatric injuries in the general child and youth population of Ontario [17], supporting a healthy immigrant effect. Our study is the first to report a loss of this health advantage over time, with immigrant injury risk converging towards levels of the general Canadian population. This is particularly important given the amenability of injury risk to appropriately targeted safety interventions [13].

The shrinking health benefit of immigrants over time may be explained by a number of factors. As immigrants acculturate, they may introduce changes to their parenting style, including direct supervision of children. With settlement and integration, children and youth may have increased exposures such as more time spent in motor vehicles with less time spent exploring urban areas as pedestrians. The worsening injury rates in immigrants may reflect adoption of unhealthy, risk taking behaviours known to contribute to injury, such as drug and alcohol use [13] or involvement with gang-related firearm violence $[27,28]$. There may also be changes in access to primary care, which has been shown to be worse over time from migration [29]. This may reduce opportunities for preventative counselling on injuries and safe play over time in Canada. Similarly, barriers to care-seeking including initial distrust in or use of the health care system may preclude recent immigrants from visiting a hospital for injuries. Conversely, our findings of increasing falls, cuts, and overexertion may indicate improved access to play spaces with increased physical activity or participation in sport by immigrants as they integrate into life in Canada.

The observed rates of cause-specific injuries by duration of residence are not unexpected. Research from Denmark has shown that while pediatric immigrants have lower risk of injury, a higher proportion scald and hot oil burns occurred in immigrants compared with native Danes [23]. More time spent at home cooking and preparing foods by immigrants, especially within newcomers, may explain this finding. Drowning rates among newcomers may be related to lack of knowledge about safe swim environments and highlights an area in need of intervention. Relatively high rates of suffocation were observed in recent immigrants. Recent immigrants may have inferior understanding of North American or European product safety guidelines such as crib safety (placing infant supine, avoiding drop-side rails, and not using loose bedding in cribs or blind cord safety), all of which can lead to entrapment or strangulation and subsequent suffocation [13]. Understanding the variability in the influence of duration of residence over time on cause-specific injuries will be important to study as injury prevention strategies are developed. For example, the unchanged rates of bicycle, pedestrian, and machinery injuries may reflect the countering protective effects of being a recent immigrant and changes in exposures over time in Canada. This remains to be studied.

We observed significant differences in risk of injury by region of origin. In particular, South and East Asian 


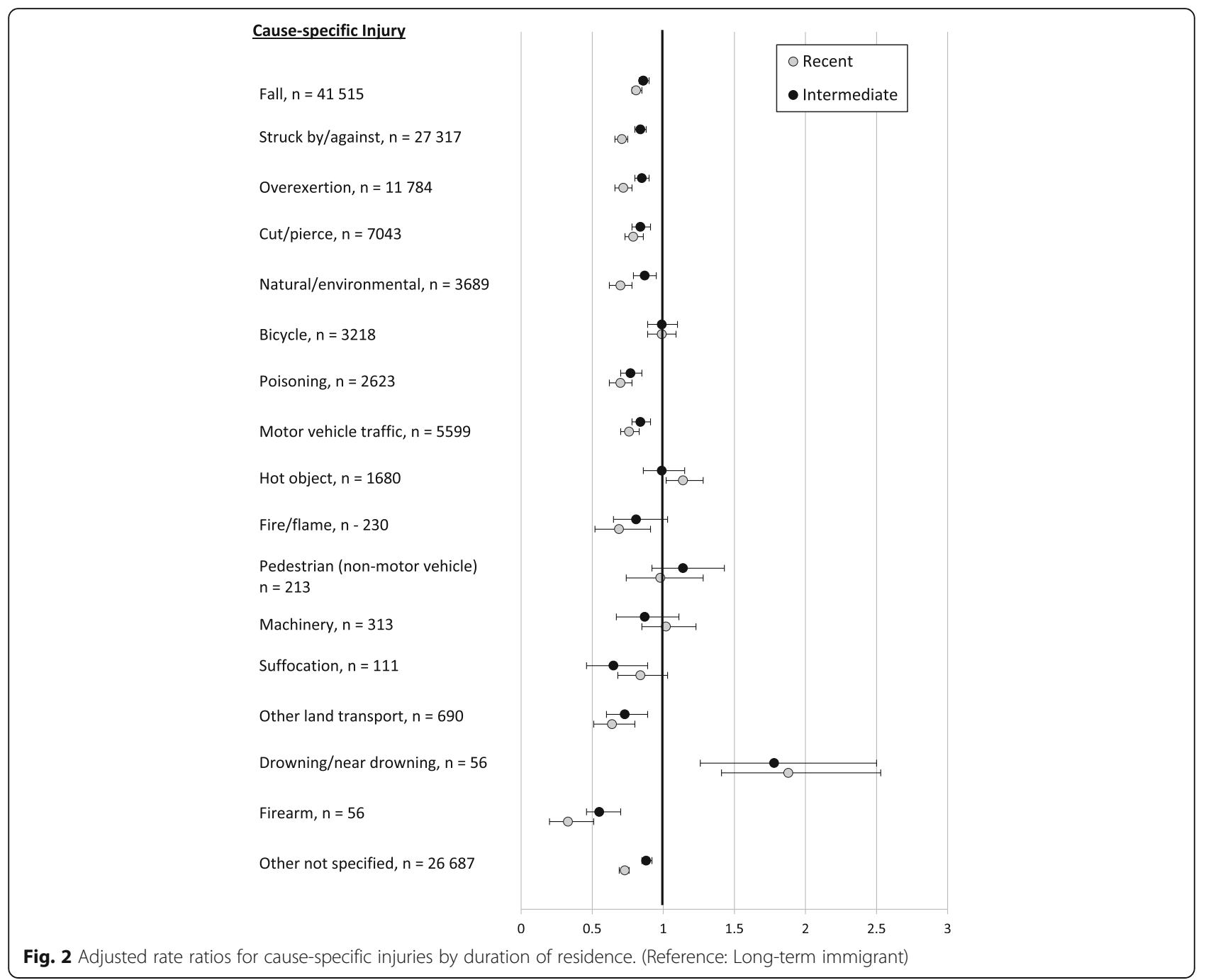

immigrant populations had very low rates of injury. Others have described significant variability in rates of injury mortality by region of origin [5] though comparisons to Asian immigrant populations have not previously been reported. Interestingly, South and East Asian immigrants have among the highest in-country unintentional injury rates across the globe (49.0 injuries per 100000 population), with rates second only to African countries [13]. Clearly, this risk is not brought with them through immigration. Our observations may be related to selection factors in those who immigrate to Canada as well as cultural differences in risk taking behaviours and exposures that reduce overall risk of unintentional injury upon arrival in Canada.

\section{Strengths and Limitations}

This is the first study to report injury risk by duration of residence in a host country. The large sample size, which included the vast majority of immigrants to Ontario, and the use of health services data to ascertain an injury event sets this study apart from other injury studies which have much smaller sample sizes [30-32] or rely on self-report which can bias results, especially for injury reporting [33]. The findings may be generalizable to many developed regions including the United States, Australia, and the European Union where large proportions of the population are foreign born, from a wide variety of countries, with similar immigration policies and comparable safety standards. However, there are a number of important limitations to our study. As it is based on registry data, this precludes our understanding of circumstances that may have contributed to injury events (i.e. supervision, intoxication, behavioural comorbidities, etc.). Other demographic information such as family education level or paternal immigrant status may have also helped to better understand injury risk over time. Our database does not include temporary or undocumented immigrants and may not be generalizable 
Table 4 Unintentional injury related emergency department (ED) visits, hospitalizations, and deaths by duration of residence and mechanism of injury, 2011 to $2012^{a}$

\begin{tabular}{|c|c|c|c|c|c|c|c|c|c|}
\hline & \multicolumn{3}{|c|}{$\begin{array}{l}\text { ED visits, } \\
\text { per } 100000 \text { immigrants }\end{array}$} & \multicolumn{3}{|c|}{$\begin{array}{l}\text { Hospitalizations, } \\
\text { per } 100000 \text { immigrants }\end{array}$} & \multicolumn{3}{|c|}{$\begin{array}{l}\text { Deaths, } \\
\text { per } 100000 \text { immigrants }\end{array}$} \\
\hline & Recent & Intermediate & Long-term & Recent & Intermediate & Long-term & Recent & Intermediate & Long-term \\
\hline Falls & 1988.9 & 2105.8 & 2195.3 & 56.9 & 62.6 & 59.2 & 0.0 & 0.0 & - \\
\hline Struck by/against & 1081.9 & 1300.5 & 1641.8 & 11.2 & 11.8 & 18.4 & - & - & - \\
\hline Overexertion & 467.9 & 538.3 & 725.3 & - & 3.7 & 4.6 & 0.0 & 0.0 & 0.0 \\
\hline Cut/pierce & 314.5 & 323.4 & 416.1 & - & - & 3.7 & 0.0 & 0.0 & 0.0 \\
\hline Natural/environmental & 151.8 & 193.8 & 208.4 & - & 2.9 & 2.7 & 0.0 & 0.0 & 0.0 \\
\hline Bicycle, no-motor vehicle & 144.5 & 157.3 & 174.2 & 4.6 & 7.1 & 6.9 & 0.0 & 0.0 & 0.0 \\
\hline Poisoning & 118.4 & 121.9 & 132.6 & 10.3 & 7.3 & 12.8 & - & 0.0 & - \\
\hline Motor vehicle traffic & 224.9 & 237.4 & 328.4 & 12.3 & 11.8 & 13.6 & - & - & 1.5 \\
\hline Hot object/scald & 109.0 & 85.6 & 71.0 & 5.7 & 5.3 & 3.9 & 0.0 & 0.0 & 0.0 \\
\hline Fire/flame & 9.1 & 10.6 & 13.1 & - & - & - & 0.0 & 0.0 & 0.0 \\
\hline Pedestrian (non-motor vehicle) & 9.4 & 11.2 & 9.6 & - & - & 1.2 & - & 0.0 & - \\
\hline Machinery & 16.5 & 13.0 & 17.1 & - & - & - & 0.0 & 0.0 & 0.0 \\
\hline Suffocation & 4.3 & 4.7 & 3.7 & 2.7 & 0.0 & 1.6 & - & - & - \\
\hline Other land transport & 22.4 & 25.5 & 43.9 & - & - & 2.5 & 0.0 & - & - \\
\hline Drowning & - & - & 1.2 & - & - & - & - & - & - \\
\hline Firearm & - & - & 2.9 & 0.0 & - & 1.3 & 0.0 & 0.0 & 0.0 \\
\hline Other or not specified & 1200.3 & 1389.6 & 1452.4 & 24.5 & 24.9 & 26.4 & - & - & - \\
\hline
\end{tabular}

${ }^{a}$ Rates for some subgroups not reported due to small cell sizes. Institutional policy requires suppression of cell sizes $<6$ or where back-calculation could allow for identification of cell sizes $<6$

to these groups. Immigrants who migrate to Ontario after landing in another province (approximately 10\%) are misclassified as non-immigrants and are not included in our study. Finally, linkage of the IRCC database to RPDB is not perfect, with a higher proportion of non-linked immigrant populations from Asia, where common names make accurate linkage more challenging [27].

\section{Conclusions}

The risk of all-cause and most cause-specific unintentional injuries in immigrant children and youth rises with increasing duration of residence in Canada. This important finding indicates there is a need to understand why this is occurring and to develop strategies, which may include providing education about water and cooking safety for recent immigrants, to maintain the immigrant health advantage over time after migration. This must be done while balancing the desire to support active living and healthy child development.

\section{Additional files}

Additional file 1: Table S1. Immigrant children and youth in Ontario by duration of residence, 2011 to 2012. Table S2. Rate ratios of unintentional injuries for immigrant children and youth aged $0-24$ years by duration of residence, 2011-2012. Descriptive table of cohort of immigrants excluding children and youth born to immigrant mothers and table of adjusted rate ratios testing the association of duration of residency in Canada and risk of unintentional injury, excluding children and youth born to immigrant mothers. (DOCX $19 \mathrm{~kb}$ )

Additional file 2: Table S3. Children and youth from immigrant families in Ontario by duration of residence, 2011 to 2012. Table S4. Adjusted rate ratios of unintentional injuries in children aged 1-24 years by duration of residence, 2011-2012. Descriptive table of cohort of immigrants excluding children less than one year of age and table of adjusted rate ratios testing the association of duration of residency in Canada and risk of unintentional injury, excluding children less than one year of age. (DOCX $13 \mathrm{~kb}$ )

Additional file 3: Table S5. Adjusted rate ratios of unintentional injuries in children and youth aged 0-24 years by duration of residence, excluding those where region of origin is missing, 2011-2012. Sensitivity analysis testing the association of unintentional injuries in children and youth by duration of residence in Canada where those whose region of origin was missing was excluded from the analysis. (DOCX $22 \mathrm{~kb}$ )

\section{Abbreviations}

Cl: Confidence interval; CIHI: Canadian Institute for Health Information; DAD: Discharge Abstract Database; ED: Emergency department; ICES: Institute for Clinical Evaluative Sciences; IRCC: Immigration, Refugees and Citizenship Canada; MOHLTC: Ministry of Health and Long-Term Care; NACRS: National Ambulatory Care Reporting System; OHIP: Ontario Health Insurance Plan; RR: RATE RATIO 


\section{Funding}

Astrid Guttmann and Alison Macpherson are funded through Applied Chairs in Child Health Services and Policy Research from the Canadian Institutes for Health Research and funding for analyses were supported through Dr. Guttmann's Chair Award. This study was supported by the Institute for Clinical Evaluative Sciences (ICES), which is funded by an annual grant from the Ontario Ministry of Health and Long-Term Care (MOHLTC). The opinions, results and conclusions reported in this paper are those of the authors and are independent from the funding sources. No endorsement by ICES or the Ontario MOHLTC is intended or should be inferred. Parts of this material are based on data and information compiled and provided by the Canadian Institute for Health Information (CIHI). However, the analyses, conclusions, opinions and statements expressed herein are those of the authors, and not necessarily those of $\mathrm{CIHI}$

\section{Availability of data and materials}

The data set from this study is held securely in coded form at the Institute for Clinical Evaluative Sciences (ICES). While data sharing agreements prohibit ICES from making the data set publicly available, access can be granted to those who meet pre-specified criteria for confidential access, available at www.ices.on.ca/DAS. The full data set creation plan is available from the authors upon request.

\section{Financial disclosure}

All authors have no financial relationships relevant to this article to disclose.

\section{Authors' contributions}

NS conceptualized and designed the study, interpreted the results, drafted the initial manuscript, revised the manuscript, and approved the final manuscript as submitted. JG and LS analyzed the data, revised the manuscript, and approved the final manuscript as submitted. AM and AG conceptualized and designed the study, interpreted the results, revised the manuscript, and approved the final manuscript as submitted. All authors approved the final manuscript as submitted and agree to be accountable for all aspects of the work.

\section{Ethics approval and consent to participate}

Ethics approval was obtained from The Hospital for Sick Children and Sunnybrook Health Sciences Centre Research Ethics Boards. Individual consent to participate was not obtained as no personal identifiers were available to investigators and individual data was anonymized.

\section{Consent for publication}

Not applicable.

\section{Competing interests}

The authors declare that they have no competing interests.

\section{Publisher's Note}

Springer Nature remains neutral with regard to jurisdictional claims in published maps and institutional affiliations.

\section{Author details}

${ }^{1}$ The Hospital for Sick Children, 555 University Avenue, Toronto, Ontario M5G $1 \mathrm{X8}$, Canada. ${ }^{2}$ Department of Pediatrics, University of Toronto, Toronto, Canada. ${ }^{3}$ Institute for Clinical Evaluative Sciences, Toronto, Canada. ${ }^{4}$ Child Health Evaluative Sciences, SickKids Research Institute, Toronto, Canada. ${ }^{5}$ York University, Toronto, Canada. ${ }^{6}$ Dalla Lana School of Public Health, Institute of Health Policy, Management and Evaluation, The University of Toronto, Toronto, Canada.

Received: 17 October 2016 Accepted: 19 July 2017 Published online: 01 August 2017

\section{References}

1. Mendoza FS. Health disparities and children in immigrant families: a research agenda. Pediatrics. 2009;124(Suppl 3):S187-95.

2. Miller LS, Robinson JA, Cibula DA. Healthy Immigrant Effect: Preterm Births Among Immigrants and Refugees in Syracuse, NY. Matern Child Health J. 2016; 20(2):484-93.
3. McDonald JT, Kennedy S. Insights into the 'healthy immigrant effect': health status and health service use of immigrants to Canada. Soc Sci Med. 2004; 59(8):1613-27.

4. Vandenheede H, Willaert D, De Grande H, Simoens S, Vanroelen C. Mortality in adult immigrants in the 2000s in Belgium: a test of the 'healthy-migrant' and the 'migration-as-rapid-health-transition' hypotheses. Trop Med Int Health. 2015;20(12):1832-45.

5. Norredam M, Olsbjerg M, Petersen JH, Laursen B, Krasnik A. Are there differences in injury mortality among refugees and immigrants compared with native-born? Inj Prev. 2013;19(2):100-5.

6. Newbold KB. Health care use and the Canadian immigrant population. Int J Health Serv. 2009;39(3):545-65.

7. Javier JR, Wise PH, Mendoza FS. The relationship of immigrant status with access, utilization, and health status for children with asthma. Ambul Pediatr. 2007:7(6):421-30

8. Setia MS, Quesnel-Vallee A, Abrahamowicz M, Tousignant P, Lynch J. Convergence of body mass index of immigrants to the Canadian-born population: evidence from the National Population Health Survey (1994-2006). Eur J Epidemiol. 2009;24(10):611-23.

9. Sordo L, Indave BI, Vallejo F, Belza MJ, Sanz-Barbero B, Rosales-Statkus M, Fernandez-Balbuena S, Barrio G. Effect of country-of-origin contextual factors and length of stay on immigrants' substance use in Spain. Eur J Public Health. 2015;25(6):930-6.

10. Guttmann A, Manuel D, Stukel TA, Desmeules M, Cernat G, Glazier RH. Immunization coverage among young children of urban immigrant mothers: findings from a universal health care system. Ambul Pediatr. 2008;8(3):205-9.

11. Kwak K, Rudmin F. Adolescent health and adaptation in Canada: examination of gender and age aspects of the healthy immigrant effect. International journal for equity in health. 2014;13(1):103.

12. Chan BTB, Schull MJ, Schultz SE. Emergency Department Services in Ontario. Toronto: Institute for Clinical Evaluative Sciences; 2001.

13. Peden M, Oyegbite K, Ozanne-Smith J. World Report on Child Injury Prevention. Geneva: World Health Organization, UNICEF; 2008.

14. Macpherson A, Spinks A. Bicycle helmet legislation for the uptake of helmet use and prevention of head injuries. Cochrane Database Syst Rev. 2007;2:CD005401

15. Ontario Building Code Act 2004 [January 6th, 2016]. Available from: http:// www.e-laws.gov.on.ca/html/source/regs/english/2004/elaws_src_regs_ r04023 e.htm. Accessed 6 Jan 2017

16. Howard AW, MacArthur C, Willan A, Rothman L, Moses-McKeag A, MacPherson AK. The effect of safer play equipment on playground injury rates among school children. CMAJ. 2005;172(11):1443-6.

17. Macpherson AK, Cernat G, Schull MJ. Injuries in Ontario. Healthc Q. 2006: 9(1):29-30.

18. Saunders NR, To T, Parkin PC, Guttmann A. Emergency Department Revisits by Urban Immigrant Children in Canada: A Population-Based Cohort Study. J Pediatr. 2016;170:218-26.

19. Saunders NR, Macpherson A, Guan J, Sheng L, Guttmann A. Unintentional injuries in children and youth from immigrant families in Ontario, Canada: a population-based cross-sectional study. CMAJ Open. 2017;5(1):E90-6.

20. Facts and figures 2013. Immigration overview - permanent and temporary residents.: Immigration, Refugees and Citizenship Canada; 2013 [cited 2016 July 19th]. Available from: http://publications.gc.ca/collections/collection_ 2015/cic/Ci1-8-9-2013-eng.pdf.

21. Institute for Clinical Evaluative Sciences Dataset Dictionary 2013 [January 6th, 2016]. Available from: https://datadictionary.ices.on.ca/Applications/ DataDictionary/Default.aspx. Accessed 8 July 2016.

22. Dissemination Area: Statistics Canada; 2012 [October 9th, 2014]. Available from: http://www12.statcan.gc.ca/census-recensement/2011/ref/dict/ geo021-eng.cfm. Accessed 4 Oct 2014.

23. Laursen $\mathrm{B}$, Moller $\mathrm{H}$. Unintentional injuries in children of Danish and foreignborn mothers. Scand J Public Health. 2009;37(6):577-83.

24. Annest $J$, Hedegaard H, Chen LH, Warner M, Smalls E. In: Control CfDCNCfIPa, editor. Proposed framework for presenting injury data using ICD-10-CM external cause of injury codes. Atlanta, GA: Centers for Disease Control and Prevention; 2014.

25. Fridman L, Fraser-Thomas JL, McFaull SR, Macpherson AK. Epidemiology of sports-related injuries in children and youth presenting to Canadian emergency departments from 2007-2010. BMC Sports Sci Med Rehabil. 2013;5(1):30. 
26. Macpherson AK, Macarthur C, To TM, Chipman ML, Wright JG, Parkin PC Economic disparity in bicycle helmet use by children six years after the introduction of legislation. Inj Prev. 2006;12(4):231-5.

27. Durbin A, Moineddin R, Lin E, Steele LS, Glazier RH. Mental health service use by recent immigrants from different world regions and by nonimmigrants in Ontario, Canada: a cross-sectional study. BMC Health Serv Res. 2015;15:336

28. Kim SY, Benner AD, Takushi RM, Ongbongan K, Dennerlein D, Spencer DK. "It's like we're just renting over here": The Pervasive Experiences of Discrimination of Filipino Immigrant Youth Gang Members in Hawai'i. AAPI Nexus. 2009:6(1):11-30.

29. Muggah E, Dahrouge S, Hogg W. Access to primary health care for immigrants: results of a patient survey conducted in 137 primary care practices in Ontario, Canada. BMC family practice. 2012;13:128.

30. Xiang H, Yu S, Zhang X, Scurlock C, Smith GA, Stallones L. Behavioral risk factors and unintentional injuries among U.S. immigrant adults. Ann Epidemiol. 2007;17(11):889-98.

31. Dudani A, Macpherson A, Tamim H. Childhood behavior problems and unintentional injury: a longitudinal, population-based study. J Dev Behav Pediatr. 2010;31(4):276-85.

32. Kahl H, Dortschy R, Ellsasser G. Injuries among children and adolescents (1-17 years) and implementation of safety measures. Results of the nationwide German Health Interview and Examination Survey for Children and Adolescents (KiGGS). Bundesgesundheitsblatt Gesundheitsforschung Gesundheitsschutz. 2007;50(5-6):718-27.

33. White HL, Macpherson AK. Capturing paediatric injury in Ontario: differences in injury incidence using self-reported survey and health service utilisation data. Inj Prev. 2012;18(1):33-7.

\section{Submit your next manuscript to BioMed Central and we will help you at every step:}

- We accept pre-submission inquiries

- Our selector tool helps you to find the most relevant journal

- We provide round the clock customer support

- Convenient online submission

- Thorough peer review

- Inclusion in PubMed and all major indexing services

- Maximum visibility for your research

Submit your manuscript at www.biomedcentral.com/submit 